\title{
Microvascular complications and their association with duration of diabetes and glycemic indices in type 2 diabetes mellitus: An Hospital based study.
}

\author{
Vivek Bhardwaj ${ }^{1}$, Harish Sharma ${ }^{1}$ \\ ${ }^{1}$ Associate professor, Department of Medicine, Government Medical College \& associate group of hospitals, Bharatpur, Rajasthan.
}

\section{Abstract}

Background: The increased incidence of diabetes rapidly globally at an alarming rate. The presence of microvascular complications has been shown to have a negative impact on patient's quality of life. There are few clinical studies in this direction but most of them lack sufficient power and are focused only towards one specific complication. Subjects and Methods: An observational single arm cross sectional study done in 100 cases of type 2 diabetes mellitus in department of medicine, Government Medical College Bharatpur, Rajasthan. Each subject underwent detailed history and complete clinical examination. Diabetes was diagnosed according to American Diabetes Association (ADA) revised criteria. Blood glucose level estimation was done by glucose oxidase method in venous blood. Glycosylated haemoglobin (HbA1C) was measured by ion-exchange chromatography method. Results: The overall male to female ratio was approx 1:1 in our study. Our study showed that the maximum patients were suffering from retinopathy $12(66.66 \%)$ in more than 10 years duration of diabetes. Mostly patients suffering from diabetic neuropathy $28(90.32 \%)$ were occurred in more than 10 years \& 5-10 years of duration of diabetes. Maximum cases of nephropathy $21(50 \%)$ were seen in 5-10 years of duration of diabetes. So proportion of neuropathy, retinopathy \& nephropathy significantly increases, when duration of diabetes increased in our results. Conclusion: Duration of diabetes was found to be a main culprit of micro vascular complication. Screening with some simple test such as ECG, fundoscopy, biothesiometer and biochemical tests namely, lipid, protein and fat profile for all cases of diabetes is essential to identify the complications at an early age.

Keywords: Diabetes mellitus, Duration of diabetes, Diabetic neuropathy, Diabetic nephropathy, Diabetic retinopathy.

Corresponding Author: Dr. Harish Sharma, Associate professor, Department of Medicine, Government Medical College \& associate group of hospitals, Bharatpur, Rajasthan.

Received: February 2019

Accepted: March 2019

\section{Introduction}

The sequel of diabetes mellitus was long term damage and failure of multiple organs such as kidneys, nerves, eyes, heart and blood vessels. Several different types of diabetes mellitus were caused by composite interaction of hereditary and geographical factors. ${ }^{[1]}$

T2DM is a metabolic and endocrine disorder represented by hyperglycemia related with resistance of insulin and/or inadequate insulin secretion. ${ }^{[2]}$ Total diagnosed cases of diabetes mellitus $(90-95 \%)$ are T2DM. ${ }^{[3]}$

Globally the number of diabetic patients expected to raise $11.4 \%$ from 366 million in 2011 to 552 million by 2030, affecting one in 10 adults. $^{[4]}$ According to the IDF (International Diabetes Foundation), the diabetes recently affected $>62$ million Indians, which is $>7.1 \%$ of the adult population. ${ }^{[4]}$ The mean age of onset is 42.5 years. Nearly 1 million people die every year in India due to diabetes. ${ }^{[5]}$

Most of the burden of T2DM is related to its micro and macro vascular complications. Microvascular complications have significant impact on morbidity, mortality and patients' quality of life. Diabetic retinopathy (DR) is one of the leading causes of blindness in the Western world. Diabetic nephropathy can lead to end-stage renal disease, which requires dialysis and/or renal transplantation and increases risk of vascular disease. Diabetic neuropathy (DN) results in the development of foot ulcers that can result in amputations, sexual dysfunction and many other unpleasant symptoms in addition to increased mortality. The presence of microvascular complications has been shown to have a negative impact on patient's quality of life. ${ }^{[6,7]}$ As a result, it is not surprising that there is great interest in improving understanding of the microvascular complications in patients with diabetes in order to develop effective strategies to treat, and ideally prevent, the development of such complications.

There are few clinical studies in this direction but most of them lack sufficient power and are focused only towards one specific complication.

\section{Subjects and Methods}


An observational single arm cross sectional study done in 100 cases of type 2 diabetes mellitus in department of medicine, Government Medical College Bharatpur, Rajasthan.

\section{Inclusion Criteria:}

All diagnosed cases of T2DM defined by ADA as FPG > $126 \mathrm{mg} / \mathrm{dl}$ and $2 \mathrm{HPG}>200 \mathrm{mg} / \mathrm{dl}$

Patients who taking specific medication for T2DM

\section{Exclusion Criteria:}

$\square \quad$ Patients with malignancy, liver disease, HBV, HCV and HIV

Diabetes.

Type 1 Diabetes Mellitus and Gestational Patient who had nephropathy before being diagnosed with Diabetes.

Patients having neuropathy due to other systemic causes eg. vitamin deficiency, drug exposure, connective tissue disorders ,thyroid disorder etc. or local causes like radiculopathies/ plexopathies.

Patients who do not provide consent.

\section{Methods:}

Each subject underwent detailed history and complete clinical examination. Diabetes was diagnosed according to American Diabetes Association (ADA) revised criteria. Blood glucose level estimation was done by glucose oxidase method in venous blood. Glycosylated haemoglobin
(HbA1C) was measured by ion-exchange chromatography method.

\section{Statistical analysis:}

Significance of difference in proportion will be inferred by Chi-square test. Significance of difference in means will be inferred by unpaired ' $t$ '-test. Association between microvascular complications and factors (duration and glycemic indices) will be inferred by Chi-square test.

\section{Results}

The overall male to female ratio was approx 1:1 in our study. 5-10 years of duration of diabetes was present in $42 \%$ cases and less than 5 years duration of diabetes was present in $40 \%$ cases [Table 1]. Our study showed that the maximum patients were suffering from retinopathy 12 $(66.66 \%)$ in more than 10 years duration of diabetes. Mostly patients suffering from diabetic neuropathy $28(90.32 \%)$ were occurred in more than 10 years \& 5-10 years of duration of diabetes. Maximum cases of nephropathy 21 $(50 \%)$ were seen in 5-10 years of duration of diabetes. So proportion of neuropathy, retinopathy \& nephropathy significantly increases, when duration of diabetes increased in our results [Table 2].

Table 1: Gender wise distribution according to duration of diabetes.

\begin{tabular}{|l|l|l|l|}
\hline Duration of diabetes & Male & Female & Total \\
\hline$<5$ yrs & 20 & 18 & 40 \\
\hline $5-10$ yrs & 22 & 20 & 42 \\
\hline$>10$ yrs & 9 & 11 & 18 \\
\hline Total & 51 & 49 & 100 \\
\hline
\end{tabular}

Table 2: Micro vascular complication according to duration of diabetes.

\begin{tabular}{|c|c|c|c|c|c|c|c|c|c|}
\hline \multirow{2}{*}{$\begin{array}{l}\text { Duration of } \\
\text { diabetes }\end{array}$} & \multicolumn{3}{|c|}{ Diabetic neuropathy } & \multicolumn{3}{|c|}{ Diabetic retinopathy } & \multicolumn{3}{|c|}{ Diabetic nephropathy (Microalbuminuria) } \\
\hline & Yes & No & P-value & Yes & No & $\mathrm{P}$-value & Yes & No & $\mathrm{P}$-value \\
\hline$<5 \mathrm{yrs}$ & 3 & 37 & $<0.0001 * * *$ & 0 & 40 & $<0.0001 * * *$ & 5 & 35 & $<0.0001 * * *$ \\
\hline $5-10$ yrs & 13 & 29 & & 6 & 36 & & 21 & 21 & \\
\hline$>10 \mathrm{yrs}$ & 15 & 3 & & 12 & 6 & & 16 & 2 & \\
\hline
\end{tabular}

\section{Discussion}

Diabetes mellitus is the commonest metabolic disorder and has a high prevalence in India. The progress of the diabetic patients largely depends on the complications seen in the natural course of illness. Chronic complications of diabetes mellitus have a significant role in increasing morbidity, mortality, disability, and health cost. The overall male to female ratio was approx 1:1 in our study. 5-10 years of duration of diabetes was present in $42 \%$ cases and less than
5 years duration of diabetes was present in $40 \%$ cases. Bharti Prakash et al $(2018)^{[8]}$ found that the patients of DM type 2 were divided into seven age groups according to their age in years 11 to 20 is the lowest and 71 to 80 years is the highest group. Tri J.E. Tarigan et al (2015) ${ }^{[9]}$ found maximum patients $(46 \%)$ were seen more than 70 years of age group. Most of the subjects who came to the clinic had experienced type 2 diabetes for more than five years and only $5 \%$ of them had been diagnosed type 2 diabetes since less than a year ago. 
Our study showed that the mostly patients suffering from diabetic neuropathy $28(90.32 \%)$ were occurred in more than 10 years \& 5-10 years of duration of diabetes, which was statistical significant $(\mathrm{P}<0.0001 * * *)$. The proportion of neuropathy significantly increases, when duration of diabetes increased in our results. Song, reported neuropathy became significantly higher in T2DM after 20 years duration. ${ }^{[10]}$ Distal symmetrical polyneuropathy shows a constant rise with duration reported by Orchard and Dorman et al. ${ }^{[11]}$

The spearmen correlation analysis showing association of various risk factors with diabetic neuropathy. The fasting blood glucose level, $2 \mathrm{hr}$. postprandial glucose level \& HbA1c was significant correlate $(\mathrm{P}<0.0001)$. Which supported our result with RP Agrawal et al (2014) ${ }^{[12]}$ found that on applying multiple regression analysis for diabetic neuropathy, a positive association revealed for duration of diabetes, blood pressure, fasting blood sugar, serum cholesterol, serum LDL and serum VLDL.

Our study showed that the maximum patients were suffering from retinopathy $12(66.66 \%)$ in more than 10 years duration of diabetes. Bharti Prakash et al $(2018)^{[8]}$ found that a positive association of age, duration of diabetes, family history of diabetes, BMI, poor diabetes control HBAIC and with retinopathy and not associated with stress and dyslipidemia.

Rema and Ponnaiya et al ${ }^{[13]}$, studied duration of diabetes, glycosylated haemoglobin, type of treatment, systolic and diastolic blood pressures and serum creatinine, showed a positive association with retinopathy but body mass index (BMI) showed an inverse association.

A study done by Ramchandran et $\mathrm{al}^{[14]}$ where they found that out of 3010 type-2 diabetics, retinopathy was present in 714 i.e. $23.7 \%$, at a diabetes centre in Chennai. Knuiman et $\mathrm{al}^{[15]}$ reported prevalence of retinopathy $28 \%$ in Perth, Western Australia. On the contrary, Rema et a113 found that the prevalence of retinopathy was $34.1 \%$ in type- 2 diabetes. It may be because of referral bias as this centre offers retinal services.

In the present study diabetic nephropathy (Microalbuminuria) was present in 42 patients i.e. $42 \%$. Klein et $\mathrm{al}^{[16]}$ in their study found that frequency of microalbuminuria was $29.2 \%$ in those taking insulin and $22.0 \%$ in those not taking insulin. Gupta et al reported prevalence of microalbuminuria in $26 \% .^{[17]}$

Our study showed that the maximum cases of nephropathy $21(50 \%)$ were seen in 5-10 years of duration of diabetes, which was statistical significant $(\mathrm{P}<0.0001 * * *)$. The fasting blood glucose level, $2 \mathrm{hr}$. postprandial glucose level \& HbA1c was significant correlate $(\mathrm{P}<0.0001)$. Significant associations of duration of diabetes with nephropathy were also observed by Mohan et al (2000) ${ }^{[18]}$ and Verghese et al (2001). ${ }^{[19]}$ Earlier, Rema et al ${ }^{[13]}$ and Ramachandran et al ${ }^{[14]}$ had also observed the positive association of hypertension with diabetic nephropathy.

\section{Conclusion}

We concluded that on applying spearman correlation for microvascular complications, a positive association was observed for age of patients, duration of diabetes, fasting blood sugar, $2 \mathrm{hr}$. postprandial glucose and $\mathrm{HbA1C}$.

\section{References}

1. Ahmed AM. History of diabetes mellitus. Saudi Med J,2002; 23: 373 378.

2. Diabetes mellitus history- from ancient to modern times.

3. Patlak M. New weapons to combat an ancient disease: treating diabetes. FASEB J ,2002;16: 1853.

4. Jumpup. Williams Textbook of endocrinology (12thed.). Elsevier/ Saunders, Philadelphia, USA, 2007; 1371-1435.

5. Zimmet PZ. Kelly West Lecture 1991. Challenges in diabetes epidemiology--from West to the rest. Diabetes Care,1992;15: 232-252.

6. Kahal H, Tahrani AA, George JT, Barlow IM, Malik MA. Obstructive sleep apnoea; a rare cause of pseudophaeochromocytoma. QJM. 2011 Nov 10. [Epub ahead of print] PubMed PMID: 22075007.

7. Zeng W, Tahrani A, Shakher J, Varani J, Hughes S, Dubb K, Stevens MJ. Effects of a synthetic retinoid on skin structure, matrix metalloproteinases, and procollagen in healthy and highrisk subjects with diabetes. J Diabetes Complications. 2011 Nov-Dec;25(6):398404.

8. Prakash B, Yadav LK. A study of micro vascular complications and associated risk factors in newly diagnosed patients of type 2 diabetes mellitus. Int J Community Med Public Health 2018;5:2338-43.

9. Tri J.E. Tarigan, Em Yunir, Imam Subekti, Laurentius A. Pramono, Diah Martina. Profile and analysis of diabetes chronic complications in Outpatient Diabetes Clinic of Cipto Mangunkusumo Hospital, Jakarta. Med J Indones. 2015;24:156-62

10. Song HS. Complication characteristics between young-onset type 2 versus type 1 diabetes in a UK population. BMJ Open Diab Res Care. 2015;3(1):1-8.

11. Orchard TJ, Dorman JS, Maser RE, Becker DJ, Drash AL, Ellis D, et al. Prevalence of complications in IDDM by sex and duration: Pittsburgh Epidemiology of Diabetes Complications Study II. Diabetes. 1990;39(9):1116-24.

12. RP Agrawal, Vipin Ola, Prashant Bishnoi, Sunil Gothwal, Parmender Sirohi,Ritvik Agrawal. Prevalence of Micro and Macrovascular Complications and their Risk Factors in Type-2 Diabetes Mellitus. JAPI • JUNE 2014 • VOL . 62: 504.508

13. Rema M, Ponnaiya M, Mohan V. Prevalence of retinopathy in non insulin dependent diabetes mellitus at a diabetes centre in Southern India. Diabetes Res Clin Pract 1996;34:29-36.

14. Ramachandran A, Snehalatha C, Satyavani K, Latha E, Sasikala R, Vijay V. Prevalence of vascular complications and their risk factors in type-2 diabetes. Journal of Assoc Physicians India 1999; 47: 1152-6.

15. Knuiman MW et al Prevalence of diabetic complications in relation to risk factors. Diabetes 1986;35:1332-39.

16. Ronald Klein, Barbara EK, Scot E Moss. Prevalence of microalbuminuria in older-onset diabetes. Diabetes Care 1993;16:1325-1330.

17. Gupta DK, Verma LK, Khosla PK, Dash SC. The prevalence of microalbuminuria in diabetes: a study from North India. Diabetes Research and Clinical Practice 1991;12:125-128.

18. Mohan V, Meera R, Premalatha G, Deepa R, Miranda P, Rema M. Frequency of proteinuria in type 2 diabetes mellitus seen at a diabetes center in Southern India. Post Grad Med J 2000;76:569-573.

19. Varghese A, Deepa A, Rema M, Mohan V. Prevalence of microalbuminuria in type 2 diabetes mellitus at a diabetes center in Southern India. Postgrad Med J 2001;77:399-402. 
Copyright: () the author(s), 2019. It is an open-access article distributed under the terms of the Creative Commons Attribution License (CC BY 4.0), which permits authors to retain ownership of the copyright for their content, and allow anyone to download, reuse, reprint, modify, distribute and/or copy the content as long as the original authors and source are cited.

How to cite this article: Bhardwaj V, Sharma H. Microvascular complications and their association with duration of diabetes and glycemic indices in type 2 diabetes mellitus: An Hospital based study. Asian J. Med. Res. 2019;8(1):ME10-ME13.

DOI: dx.doi.org/10.21276/ajmr.2019.8.1.ME4

Source of Support: Nil, Conflict of Interest: None declared. 